\title{
EFEITOS LINGUÍSTICOS NA VARIAÇÃO DE QUEDA DE SÍLABA EM CAPIVARI-SP E CAMPINAS-SP ${ }^{1}$
}

\author{
ENEIDA DE GOES LEAL*
}

\begin{abstract}
RESUMO: Este artigo apresenta resultados parciais de Leal (2012) a respeito de efeitos internos sobre a queda de sílaba, comparando-se como o processo é implementado em Capivari-SP e Campinas-SP. Prosódia foi a única variável com um efeito igual nas duas cidades: houve um (leve) favorecimento do processo entre frases fonológicas. Houve dois resultados semelhantes: para Estrutura Silábica, duas sílabas CV favorecem levemente a queda de sílaba em Capivari mas têm efeito neutro em Campinas, sendo que o fator mais relevante para a aplicação do processo é a estrutura da sílaba sujeita ao apagamento (nas duas cidades); para Métrica, há uma tendência ao PAR (Selkirk 1984: 19), mas, diferentemente de Alkmim e Gomes (1982), contextos com choque de acento não são bloqueados, mas desfavorecidos. Por fim, houve diferenças: a variável Número de Sílabas foi selecionada somente em Capivari, enquanto Frequência de Uso de Palavras, apenas em Campinas. Portanto, conclui-se que o processo é implementado diferentemente nas duas cidades.
\end{abstract}

Palavras-chave: queda de sílaba; estruturas silábica e métrica; prosódia.

ABSTRACT: This paper presents partial results of the internal effects on syllable drop from Leal (2012), comparing how the process is implemented in Capivari-SP and Campinas-SP. Prosody was the only equal effect in both cities: phonological phrase slightly favors syllable drop. There were two similar results: for Syllable Structure, two CV syllables are slightly favored in Capivari and neutral in Campinas. What seems to be important for this variable is the structure of the syllable undergoing deletion in both cities. Concerning Metrics, there is a tendency to PRA (Selkirk 1984: 19). Differently from Alkmim and Gomes (1982), Metrics has shown that stress clash does not block the process, but disfavor it instead. Finally, different effects were also found between the cities: Number of Syllables was selected only in Capivari, while Word Frequency usage only in Campinas. Therefore, the conclusion is that syllable drop is implemented differently in the two cities.

Keywords: syllable drop; syllable and metrical structures; prosody.

\section{INTRODUÇÃO}

O presente artigo traz os resultados parciais da tese de Leal (2012), em que se analisou a variação de queda de sílaba nos dialetos de Capivari e Campinas. O principal objetivo é comparar as duas cidades

* Universidade de São Paulo (USP), Departamento de Linguística, São Paulo, SP, Brasil. eneidaleal@yahoo.com

${ }^{1}$ Agradeço aos dois pareceristas anônimos pelos comentários e importantes observações colocadas. Problemas remanescentes são de minha reponsabilidade. 
e verificar quais são as semelhanças e as diferenças nos resultados, exclusivamente das variáveis linguísticas.

A queda de sílaba pode ser definida como um processo em que a adjacência de duas sílabas que tenham determinados traços fonológicos iguais ou semelhantes (cf. detalhamento na seção 2) permite que uma delas seja apagada. Assim, há duas variantes na variável dependente (aplicação ou não aplicação do processo), como nos exemplos a seguir (cf. Leal 2012: 82): ${ }^{2}$

(1) aplicação de queda de sílaba:

... a gen(TE) TAva fazendo os cálculos.

(2) não aplicação de queda de sílaba

... a genTE TAva no céu, né?

Em (1) e (2), o contexto segmental sujeito à queda é formado pelas vogais $/ e+a /$ e há duas consoantes $/ \mathrm{t}+\mathrm{t} /$ idênticas. O que se nota é que esse contexto apresenta variação do processo, já que pode ser proferido aplicando-se de queda de sílaba (cf. (1)) ou sem aplicá-la (ver (2)).

Neste trabalho, foram utilizadas a geometria de traços (Clements e Hume 1995) e a sociolinguística laboviana de quantificação dos dados (cf. seção 3). Assim, num dado contexto segmental, as possibilidades de aplicação ou não aplicação de queda de sílaba foram contadas e, a partir dessas quantificações, verificou-se quais interferências linguísticas podem atuar no processo em ambas as cidades - de modo a favorecê-lo ou inibi-lo. Algumas questões linguísticas a serem discutidas são:

- Duas sílabas iguais (como em depen(DE) DE dinheiro) favorecem mais o processo do que sílabas diferentes (por exemplo, CCVC + CV: quilome(TROS) DE mata)? Sílabas diferentes inibem-no?

- Sílabas com estrutura CV favorecem/inibem o processo?

- Que tipo de estrutura métrica favorece/inibe o processo?

- Que tipo de estrutura prosódica favorece/inibe o processo?

- Há alguma interferência do tamanho fonológico? Se houver, como o número de sílabas da palavra interfere no processo?

- Há interferência de frequência de uso de palavras? Ou seja, há diferenças na aplicação se a palavra for muito frequente, frequente ou rara?

A partir dessas questões gerais para se investigar efeitos linguísticos (suprassegmentais e lexicais) do processo, busca-se verificar se as restrições são iguais ou diferentes em Capivari e Campinas, observando-se também como o processo é descrito na literatura (cf. referências apresentadas na seção 2).

${ }^{2}$ No presente artigo, os parênteses indicam queda de segmento(s); as sílabas do contexto segmental estão destacadas em maiúsculas; o símbolo * indica agramaticalidade da sentença; e as transcrições fonéticas apresentadas seguem o Alfabeto Fonético Internacional (IPA). Os exemplos provêm do corpus de Leal (2012) (se forem de outro autor, estão especificados) e estão, em sua grande maioria, limitados à aplicação de queda de sílaba - exemplos de não aplicação do processo foram omitidos, mas, em todos eles, houve variação de queda de sílaba (cf. Leal 2012). 
A escolha das cidades foi feita a partir de minha dissertação de mestrado (Leal 2006), uma vez que os resultados apontaram que o contexto segmental de queda de sílaba em Capivari é mais abrangente (em termos de traços fonológicos) do que aqueles reportados na literatura (cf. seção 2). Dito de outro modo, os contextos segmentais considerados gramaticais em Capivari (nos testes e nas entrevistas) são agramaticais para falantes de cidades próximas.

Campinas foi eleita para o estudo sistemático com Capivari porque, impressionisticamente, os campineiros pareciam implementar o processo nos moldes em que ele é descrito pela literatura.

Outros fatores foram levados em conta, como a formação das duas cidades (que foi bastante semelhante): no Brasil colônia, exploradores e bandeirantes em busca de ouro saíam de São Paulo rumo ao Mato Grosso e, nesses caminhos, formavam-se acampamentos e, mais tarde, vilarejos. Nesses lugares, desenvolviam-se cidades, e Campinas e Capivari foram estabelecidas em $1774 \mathrm{e}$ 1832, respectivamente.

Quanto à urbanização, o quadro socioeconômico dos anos 80 em Campinas se torna semelhante ao atual: pessoas do nordeste e do sul do país migram para essa cidade, em busca de trabalho. Em Capivari, uma das bases econômicas atuais ainda é a cana de açúcar, embora haja indústrias (de bebida e de tecelagem) e estabelecimentos comerciais. Campinas é quase 2,5 vezes maior do que a de Capivari: Campinas tem uma população de 1.080.999 de habitantes e Capivari tem 48.573 habitantes (dados do IBGE 2010). Assim, pode-se considerar que há, de um lado, uma cidade grande e, de outro, uma cidade pequena.

Outro fator levando em consideração para a escolha das cidades está relacionado aos dialetos: o modo de falar capivariano é classificado na literatura como pertencente ao dialeto caipira (Amaral 1920 e Garcia 2009a, 2009b). No que se refere ao dialeto campineiro, Leite (2004) trabalhou com 8 estudantes em Campinas, e que são de São José do Rio Preto (isto é, outra cidade do interior paulista). Foi verificado que há um prestígio do dialeto campineiro por parte destes estudantes rio-pretenses: para eles, o campineiro tem uma fala socialmente menos marcada (cf. Leite 2004: 132) do que nas outras cidades do interior paulista. A autora conclui que o dialeto de Campinas parece ser uma fala intermediária: é uma cidade do interior, mas o dialeto tem mais prestígio do que o caipira (cf. Leite 2004: 97-113).

Assim, o interesse foi buscar quais são as diferenças e semelhanças da queda de sílaba no interior de São Paulo: de um lado, uma cidade grande que é um dos grandes centros urbanos do Brasil e, de outro, uma cidade tipicamente interiorana.

Este artigo está estruturado da seguinte maneira: na seção 2, está apresentada a definição e a literatura de queda de sílaba; a seção 3 traz a metodologia da pesquisa; os resultados estão apresentados na seção 4 , em que são comparadas as implementações de queda de sílaba em Capivari e Campinas; a seção 5 expõe a conclusão; finalmente, as referências estão na seção 6 . 


\section{A QUEda de Sílaba NA Literatura E A DEFIniÇão do PROCESSO}

Ainda que o contexto segmental de queda de sílaba não seja o foco deste artigo e tenha sido estudado em outros trabalhos (cf. Leal 2006, 2007, 2012, 2018), é necessário apresentar o funcionamento desse nível fonológico, uma vez que o processo é definido por meio dele.

Nos resultados de Leal (2006, 2007, 2012, 2018), pôde-se observar que definir a queda de sílaba depende basicamente do contexto consonantal: numa sequência de duas sílabas (em que a primeira deve ser fraca, cf. Tenani 2002), a primeira delas pode ser apagada se as duas consoantes tiverem um mesmo ponto de $\mathrm{C}$ e um mesmo valor para o traço [contínuo] (cf. geometria de traços, Clements e Hume 1995). Em outras palavras, há variação de queda de sílaba somente se as duas consoantes tiverem uma mesma cavidade oral, como mostram os exemplos a seguir:

(3) $/ \mathrm{d}+\mathrm{n} / \quad$ senta(DOS) NUM canto

(4) $/ \mathrm{s}+3 / \quad$ cabe(ÇA) GIgante

(5) $/ \mathrm{t}+\mathrm{d} / \quad \operatorname{limi}(\mathrm{TE}) \mathrm{DE}$ palavra

(Alkmim e Gomes 1982: 49)

(6) $/ d+d / \quad$ faculda(DE) DE letras

(Alkmim e Gomes (1982: 48)

(7) $/ \mathrm{t}+\mathrm{tr} / \quad$ quan(TO) TRAbalho

(Alkmim e Gomes (1982: 48)

(8) $\quad / \mathrm{v}+\mathrm{b} / \quad *$ viú(VA) BOnita

(9) $/ 3+v / \quad *$ igre(JA) VAzia

(10) $/ \mathrm{d}+\mathrm{v} / \quad$ *pare(DE) VERmelha

Em (3), há duas consoantes coronais [-contínuo] que são diferentes no traço [nasal] (a primeira é oral e a segunda é nasal); em (4), há também duas coronais e ambas são [+contínuo]; em (5), a única diferença entre as consoantes coronais [-contínuo] $/ \mathrm{t}+\mathrm{d} /$ é que a primeira é [-vozeado] e a segunda é [+vozeado]; em (6), as consoantes $/ d+d /$ são idênticas; e em (7), o contexto é formado por duas consoantes também idênticas $/ t+t /$, desta vez, [-vozeado], e a consoante $/ r /$ do ataque ramificado na primeiro sílaba da palavra trabalho não apresenta obstáculo à aplicação do processo (a segunda sílaba do contexto pode ser CCV, segundo Alkmim e Gomes 1982: 48). Assim, nos exemplos (3)-(7), a cavidade oral das consoantes é a mesma, isto é, o ponto de C e [contínuo] são iguais nas duas consoantes e há variação de queda de sílaba.

No exemplo (8), as duas consoantes $/ \mathrm{v}+\mathrm{b} /$ são labiais, mas a primeira é [+contínuo], e a segunda, [-contínuo]; em (9), as consoantes /3 + v/ são [+contínuo], mas a primeira é uma coronal e a segunda é uma labial; em (10), as consoantes $\mathrm{em} / \mathrm{d}+\mathrm{v} /$ são diferentes nos dois nós da cavidade oral, já que a primeira é uma coronal, enquanto que a segunda é uma labial; /d/ é [-contínuo] e /v/é [+contínuo]. Nesses três últimos casos, a queda de sílaba categoricamente nunca ocorre: em (8) as consoantes são diferentes no traço [contínuo]; em (9), a diferença está no ponto de C; e, em (10), ambos o ponto de C e o valor para [contínuo] são diferentes. Como se pode observar, é necessário que as consoantes tenham um mesmo ponto de $\mathrm{C} \mathrm{e}$ 
um mesmo valor para o traço [contínuo] para que haja variação; se as consoantes forem diferentes nesses traços, o processo é bloqueado, isto é, é categórico para nunca ocorrer.

A queda de sílaba pode ser interpretada como dois processos fonológicos:

- na elisão silábica (Leal 2006, 2007, 2012, Oliveira 2012, Oliveira e Viegas 2013), os traços internos às consoantes podem ser diferentes em [nasal] (cf. (3)) ou em [ \pm anterior, \pm distribuído] (ver (4)); e

- na haplologia (Alkmim e Gomes 1982, Bisol 2000, Tenani 2002, Battisti 2004, 2005, Pavezi 2006, Leal 2006, 2007, 2012, Mendes 2009, Simioni e Amaral 2011, Oliveira 2012, Oliveira e Viegas 2013, Oliveira e Paz 2013, Paz 2013) os traços são limitados à diferença do traço [ \pm vozeado] (cf. (5)).

Esses autores trabalharam com diferentes dialetos do português brasileiro: Alkmim \& Gomes (1982) não afirmam qual é o dialeto estudado, e definem-no como "sotaque brasileiro" (p. 44); Tenani (2002, 2003) estudam o dialeto de São José do Rio Preto; Battisti (2004) analisa o de Porto Alegre; Bisol (2000) também não define qual a variedade estudada, chamando-a de "dialetos populares" do português brasileiro (p. 406); Pavezi (2006a) analisa os dialetos de São Paulo (corpus NURC-SP) e de São José do Rio Preto (corpus IBORUNA-SJRP); finalmente, Leal $(2006,2007)$ estudam o falar da cidade de Capivari. Como se verá em 3.1, há muitos pontos nos resultados desses trabalhos que são diferentes, e essa diferença pode estar no fato de serem comunidades distintas. Em outras palavras, a queda de sílaba parece se aplicar de modo diverso, a depender da distribuição geográfica dos falantes.

Embora separadas na literatura, a elisão silábica e a haplologia podem ser entendidas como um único processo fonológico, como apontam os resultados de Leal (2006), já que têm as mesmas propriedades nos seguintes níveis:

- no contexto segmental, é necessário que as consoantes tenham um mesmo ponto de $\mathrm{C}$ e um mesmo valor para [contínuo];

- no nível prosódico (cf. subseção 3.1), a elisão silábica e a haplologia podem ser aplicadas em qualquer constituinte (o que corrobora Tenani 2002, Battisti 2004 e Pavezi 2006 para a haplologia; e Leal 2006 para a elisão silábica e haplologia); a fronteira de frase fonológica apresentou uma propensão à elisão silábica e à haplologia, resultados semelhantes (para a haplologia) aos de Battisti (2004, p. 32) (dentro de frase fonológica) e Pavezi (2006, p. 51) (dentro de frase fonológica para fala espontânea e em fronteira de frases fonológicas para fala experimental);

- na métrica, os processos resultam num ritmo com tendência ao Princípio de Alternância Rítmica (PAR - cf. Selkirk 1984: 19) e, interessantemente, a aplicação de ambos pode resultar em choque acentual - isto é, não há bloqueio se o resultado for duas sílabas fortes adjacentes (diferentemente dos resultados de Alkmim e Gomes 1982, p. 51 - cf. a formalização da regra). 
Com base nesses resultados, a elisão silábica e a haplologia são tratados aqui como um único processo: a queda de sílaba.

\section{METODOLOGIA}

A fim de verificar as características de queda de sílaba, foi utilizada a geometria de traços para distinguir o que é variável do que é categórico. Assim, há contextos em que pode haver ou não aplicação de queda de sílaba (isto é, há variação) - cf. exemplos (3)-(7) na seção 2. Por exemplo, (3) pode ser dito sem a queda de sílaba, como sentaDOS NUM, ou com a aplicação do processo, como senta(DOS) NUM; da mesma forma, a queda de sílaba pode variar nos exemplos (4)-(7). É possível também determinar ambientes em que o processo nunca pode ser aplicado, como nos exemplos (8)-(10) na seção 2, em que a cavidade oral é diferente.

O emprego da sociolinguística variacionista (Labov 1972, 1994, 2001) foi oportuno para verificar como se relacionam os grupos de fatores internos, a depender: (i) da tendência, isto é, se o processo é favorecido, neutro ou desfavorecido numa determinada variante; (ii) e da produtividade, expressa via pesos relativos. ${ }^{3}$ Os dados foram analisados estatisticamente com o auxílio do software GoldVarb (cf. Sankoff, Tagliamonte \& Smith 2005) e as variáveis ${ }^{4}$ foram interpretadas do seguinte modo:

a) iguais: se há uma mesma tendência e uma mesma produtividade (isto é, os pesos relativos são próximos);

b) semelhantes: há uma mesma tendência, mas a produtividade é diferente (ou seja, pesos relativos diferentes); e

c) diferentes: se as tendências são diferentes (e, consequentemente, os pesos relativos também são diferentes); ou se um grupo de fatores foi selecionado numa cidade e não em outra.

O corpus é composto de 48 horas de gravação, ${ }^{5}$ com 24 informantes campineiros e 24 capivarianos, e os tokens computados são contextos em que as consoantes são iguais na cavidade oral (portanto, ambientes de variação).

\footnotetext{
${ }^{3}$ Os pesos relativos foram interpretados seguindo-se Tagliamonte (2006, p. 156). A autora explica que, na literatura, é comum encontrar interpretações de que pesos relativos acima de 0.50 favorecem uma variante, enquanto que aqueles que estão abaixo de 0.50 desfavorecem-na. Entretanto, como o próprio nome (no português) sugere, é mais apropriado interpretar esses pesos como sendo relativos entre si. Por exemplo, se uma variante apresentar p.r. $=0.49$ e a outra p.r. $=0.51$, a interpretação é que essas duas variantes são neutras ao processo.

${ }^{4}$ A amostra foi estratificada do seguinte modo: foram 2 fatores para Cidades (Capivari e Campinas) × 2 fatores para Escolaridade (ensino fundamental e ensino superior) $\times 2$ fatores para Gênero (masculino e feminino) x 2 fatores para Faixa Etária $(20-35$ anos e mais de 50) = 16 × 3 informantes por célula $=48$ Informantes (48 horas gravadas).

${ }^{5}$ Nas entrevistas sociolinguísticas, buscou-se o vernáculo (cf. Labov 1972: 208), e os temas foram, basicamente, cinco: infância, adolescência, namoro/casamento, trabalho, ponto de vista do informante com relação à sua cidade natal (como era, como está hoje em dia). Se o informante não seguisse os 5 temas, não houve intervenção da pesquisadora, ou seja, o mais importante foi deixar a entrevista fluir.
} 
A variável dependente é binária: apagar a sílaba ou produzi-la. Esses dois "modos de se dizer a mesma coisa" (Labov 1972) variam a depender dos tipos de contextos em que se inserem (sociais e linguísticos). Esses ambientes são condicionamentos que "pressionam" a preferência do falante por uma forma ou outra (apagar a sílaba ou não), e são interpretadas pelo pesquisador via hipóteses, com as quais são construídos os grupos de fatores independentes.

O método para se retirar os dados do corpus e analisá-los foi feito com a ajuda de dois programas: o Excel, para codificar e armazenar os dados; e o Praat (Boersma e Weenink 2010), utilizado para fazer análises dos espectrogramas e/ou análises de oitiva. ${ }^{6}$

Outro ponto metodológico importante a se apresentar diz respeito à fonética. Nas gravações, em consequência de se buscar o vernáculo, os sons não são tão perfeitos quanto os de testes numa cabine acústica. ${ }^{7}$ Então, se o segmento parece ter sido apagado (não aparece a soltura de um /t/, por exemplo), mas o tempo dele permaneceu, esses contextos foram contados como não aplicação de queda de sílaba, isto é, a sílaba não foi totalmente apagada. Casos extremos foram excluídos da análise, e são aqueles em que o espectrograma, os formantes ou o pitch não ajudaram na percepção para definir se houve ou não a aplicação da queda de sílaba. Nas análises dos espectrogramas com o Praat, a frequência default utilizada foi visualizar os sons a $6 \mathrm{kHz}$, que variou a depender do segmento (por exemplo, com as fricativas, a frequência foi aumentada para a faixa de $10 \mathrm{kHz}$ ou $12 \mathrm{kHz}$ ), ou do sexo do informante. Em todos os contextos com a possibilidade de aplicação do processo, a janela era passada para a faixa de 0,5 a 1 segundos. Nos TextGrids, ${ }^{8}$ foram marcados, além do tempo da ocorrência, também os segmentos relevantes do contexto - em todas as 5628 ocorrências. Portanto, todos os contextos de queda de sílaba foram checados nos espectrogramas.

Na próxima seção, estão as hipóteses e as variáveis linguísticas deste trabalho.

${ }^{6}$ Ainda, foram estabelecidas 7 restrições na extração dos tokens, resumidas a seguir: (i) as sílabas do contexto de queda devem ter, pelo menos, uma consoante no ataque, uma vez que o processo é condicionado por esses segmentos (de outro modo, contextos $\mathrm{V} \# \mathrm{~V}$ podem produzir outros processos fonológicos que não a queda de sílaba, tais como: a degeminação, como carrO Oficial $>$ carr[o] ficial; a ditongação, como em carrO Estacionado > carr[we]stacionado ou a elisão, como em carr[i] stacionado); (ii) empréstimos foram codificados de acordo com a fonologia do português, como em $c l u b>$ /'klu.be/, em que a sílaba final da palavra é aberta, com /e/ final (diferentemente do inglês, em que as sílabas finais são travadas /' $\mathrm{kl} \Lambda \mathrm{b} /$ ) - cf. Câmara, 1969, p. 28); (iii) as consoantes têm as mesmas cavidades orais (cf. Leal 2006 e o estudo piloto em Leal 2012); (iv) A primeira sílaba do contexto deve ser fraca para que haja variação de queda de sílaba (para haplologia, cf. Alkmim e Gomes 1982, Bisol 2000, Pavezi 2006 e Tenani 2002, 2003, 2006), sem importar o acento nas sílabas adjacentes; (v) os dados considerados foram aqueles de fala neutra, delimitados de acordo com o nível da frase entonacional (não foram computados casos de hesitação, ênfase e momentos em que o informante riu); (vi) para computar os tokens ou retirá-los da análise, a frase entonacional foi tomada como limite; (vii) finalmente, casos de apagamento de clítico fonológico não foram analisados (serão estudados em trabalhos futuros).

${ }^{7}$ A fim de minimizar esse efeito, as gravações eram marcadas logo ao alvorecer ou à noite, a depender da disponibilidade do informante - nesses períodos, ruídos externos (da rua, de carros) são reduzidos.

${ }^{8}$ Um TextGrid é um objeto do Praat em que são anotados os segmentos, inserindo-se linhas divisórias entre eles. 


\section{As hipóteses e os grupos de fatores linguísticos}

Em Leal (2012), há 14 variáveis independentes ${ }^{9}$ e, neste artigo, estão apresentadas as cinco variáveis linguísticas. Optou-se por apresentar exclusivamente as variáveis internas a fim de poder mostrar os resultados linguísticos mais detalhadamente. ${ }^{10}$

A primeira variável a ser apresentada é a Estrutura Silábica, cuja hipótese foi formulada com base nos trabalhos de Alkmim e Gomes (1982), Battisti (2004), Pavezi (2006) e Leal (2006). Segundo Alkmim e Gomes (1982), a haplologia só é possível se a primeira sílaba do contexto for $\mathrm{CV}$ - do contrário, há bloqueio do processo. Ao estudar a relação entre acento e estrutura silábica, Collischonn (2007) analisa processos fonológicos de sândi interno e externo ${ }^{11}$ e, dentre estes, a haplologia. A autora verificou que a estrutura silábica não interfere neste processo fonológico (pp. 221-2), já que as sílabas do contexto subjacente são bem-formadas; o que desencadeia a haplologia é uma exigência de propriedades segmentais, o Princípio do Contorno Obrigatório (OCP). ${ }^{12}$ Contudo, Battisti (2004: 31), Pavezi (2006, p. 33) e Leal (2006: 130) encontraram casos em que a sílaba sujeita ao apagamento tem uma estrutura $\mathrm{CCV}$, como em dentro de. No corpus deste trabalho, também houve exemplos em que a sílaba à esquerda tem uma estrutura diferente de $\mathrm{CV}$, como apresentado a seguir:

$$
\begin{array}{lll}
/ \text { tre/ } & \mathrm{CCV}+\mathrm{CV}: & \text { ven(TRE) DA terra } \\
/ \text { ter/ } & \mathrm{CVC}+\mathrm{CV}: & \text { shopping cen(TER) DE Campinas }
\end{array}
$$

Há uma possibilidade de que as sílabas /tre/ se realizem com o apagamento de $/ \mathrm{r} /$, como em dentro $>$ den[to], centro $>$ cen[to]; outro $>$ ou[to]. Da mesma forma, sílabas $\mathrm{CVC} / \mathrm{ter} /$ podem ser simplificadas para $\mathrm{CV}$, como em revólver > revólve; açúcar > açúca; hambúrguer > hambúrgue. Assim, haveria uma ordenação de regras na queda de sílaba: (i) elisão consonantal $(\mathrm{CCV}>\mathrm{CV})$ : a sílaba $\mathrm{CCV}$ em venT(R)E DA terra passaria a $\mathrm{CV}$, venTE; e (ii) queda de sílaba $(\mathrm{CV}>\varnothing)$ : a partir do contexto $\mathrm{CV}+\mathrm{CV}$, a primeira sílaba se apagaria, formando ven(TE) DA terra. Há, talvez, duas causas (dentre outras) para a simplificação silábica: (i) taxa de elocução mais rápida: contextos em que as palavras tenderiam a uma

${ }^{9}$ São 4 grupos de fatores do contexto segmental (Igualdade de Segmentos, Cavidade Oral das Consoantes, Cavidade Oral das Consoantes com Distinção do Traço [nasal] e Cavidade Oral das Vogais), outros 5 grupos de fatores linguísticos e 5 grupos de fatores sociais (Escolaridade, Gênero, Faixa Etária, Informante e Cidade).

${ }^{10}$ As variáveis internas do contexto segmental estão detalhadas em Leal (2006, 2007, 2017, 2018). Quanto às externas, não foram selecionadas em nenhuma das rodadas feitas por Leal (2012), o que corrobora o estudo de haplologia no dialeto porto-alegrense: Battisti (2005: 79) explica que esse processo é relativamente despercebido pelos falantes e, por isso, há uma preponderância das variáveis linguísticas sobre as sociais.

${ }^{11}$ Um sândi interno é um tipo de processo fonológico que se dá abaixo da palavra e um sândi externo acontece em níveis acima desse nível.

${ }^{12}$ O OCP foi primeiramente proposto por Leben (1973) para línguas tonais, e muitos outros autores trabalham com esse princípio (cf. McCarthy 1979, 1986; Goldsmith 1990). McCarthy (1988: 88) reformulou-o do seguinte modo: "Adjacent identical elements are probibited." 
maior simplificação; e (ii) difusão lexical: de acordo com Cristófaro (2001: 211), os difusionistas "sugerem que uma mudança sonora é aplicada a algumas palavras e pode atingir (ou não) o léxico como um todo". Portanto, é a palavra que muda em relação a sons específicos."13

Paz (2013) e Oliveira e Paz (2013) trabalharam com narrativas em seu corpus, e encontraram um resultado inesperado: duas sílabas $\mathrm{CCV}+\mathrm{C}(\mathrm{C}) \mathrm{V}$ favorecem a haplologia, enquanto que sílabas $\mathrm{CV}+\mathrm{CV}$ a desfavorecem. Analisando esses dados de perto, as autoras verificaram que, dos 50 dados com aplicação de haplologia, 93\% correspondem a contextos em que a primeira palavra é dentro (cf. Paz 2013: 69-70 e Oliveira e Paz 2013: 78). Assim, a interpretação nesses trabalhos é que há favorecimento de aplicação do processo nesse item lexical porque a haplologia com dentro não causa perda informacional e é mais facilmente recuperada pelo falante. A seguir, estão os fatores propostos para a variável Estrutura Silábica e seus respectivos exemplos: ${ }^{14}$

$$
\begin{aligned}
& \mathrm{CV}+\mathrm{CV} \\
& \mathrm{CVC}+\mathrm{CVC} \\
& \mathrm{CCV}+\mathrm{CCV} \\
& \mathrm{CV}+\text { outros } \\
& \mathrm{CVC}+\text { outros } \\
& \mathrm{CCV}+\text { outros } \\
& \text { outros + outros }
\end{aligned}
$$

\author{
2 бs simples \\ 2 os com coda ramificada \\ 2 os com ataque ramificado \\ $\sigma$ simples + outra estrutura \\ $\sigma$ com coda + outra \\ $\sigma$ com ataque ramificado + outra \\ duas $\sigma \mathrm{s}$ com outras estruturas
}

\author{
beira(DA) DA pista \\ dos ne(TOS) DOS outros ${ }^{15}$ \\ ia sem(PRE) PRA casa \\ po(DE) DEIxar \\ ver os ami(GOS) CREscer \\ o semes(TRE) TAMbém \\ previdên(CIA) SOcial
}

Há variação de queda de sílaba em contextos como (13), em que as estruturas silábicas são CV; em (14), há duas estruturas com coda; em (15), há possibilidade de aplicação do processo com sílabas com ataque ramificado; no exemplo (16), a primeira sílaba é CV, seguida de outros tipos de estruturas, como no exemplo, em que a segunda sílaba é um ditongo $\mathrm{CVg}$ - na realização fonética, pode ser produzida com a perda do glide, e deixa pode ser produzido como ['de.fe]); o exemplo (17) é um caso em que uma sílaba com coda aparece seguida de outros tipos de estrutura, como uma sílaba CVC seguida de uma CCV de crescer; em (18), há uma sílaba com ataque ramificado /tre/ seguida de um sílaba/taN/ com coda nasal; em (19) há duas sílabas constituídas de outros tipos de estruturas, diferentes de CV, CCV e CVC - em previdên(CIA) SOcial, a primeira sílaba é CVV, um hiato fonológico, e está seguida de uma sílaba simples.

\footnotetext{
${ }^{13}$ Agradeço ao professor Emilio Gozze Pagotto e à professora Luciani Tenani por me chamarem a atenção a estas possibilidades de análise.

${ }^{14}$ Neste artigo, o símbolo $\sigma$ indica sílaba.

${ }^{15}$ Chamamos a atenção para a possibilidade, nesse exemplo (14), os ne(TOS) DOS, de o /s/ de sentados poder ser apagado antes da aplicação da queda de sílaba, pois é a $2^{\mathrm{a}}$ marca de plural no sintagma nominal oS netoS, que pode ser proferido como oS neto. Desse modo, haveria uma simplificação da sílaba de $\mathrm{CVC} /$ tos/ de netoS para uma estrutura $\mathrm{CV} /$ to/ neto(S). A pergunta que se coloca é: como se dá a ordenação de regras nestes casos de apagamento, em que parece haver um efeito da morfologia na queda de sílaba? Esta é uma questão que foge do escopo deste trabalho, a ser estudada futuramente. Agradeço à $\operatorname{Prof}^{a} \mathrm{Dr}^{\mathrm{a}}$ Ester Mirian Scarpa por me chamar a atenção para este tema.
} 
A hipótese para esta variável é que quanto mais leve for a sílaba sujeita ao apagamento, maior será a tendência à queda. Ademais, se as sílabas sujeitas ao apagamento tiverem coda, a hipótese é que há um desfavorecimento do processo. Finalmente, com relação a estruturas $\mathrm{CCV}$, não temos uma hipótese, mas o intuito é verificar como o processo se dá se a sílaba sujeita à queda tiver uma consoante na segunda posição do ataque. De modo informal, a pergunta para estruturas CCV é: a segunda consoante do ataque "atrapalha" a queda de sílaba ou é inerte?

Para a segunda variável, a Métrica, a hipótese levantada está relacionada à sequência de acentos da primeira e da segunda palavras: o resultado de queda de sílaba deve ter uma tendência ao PAR. Dessa forma, a aplicação do processo deverá fazer com que os acentos sejam intercalados por uma ou duas sílabas fracas, no máximo, com o propósito de otimizar o ritmo.

Na literatura, há os seguintes trabalhos com respeito à Métrica: para Mendes (2009: 89-90), se ambas as sílabas são fracas, há favorecimento de haplologia, e se a segunda sílaba for forte, há um desfavorecimento do processo (com a atuação do OCP); para Oliveira (2012: 218), também há atuação do OCP agindo no apagamento da sílaba; no entanto, nesse mesmo contexto, se a segunda sílaba for acentuada, há outro princípio agindo, o PAR, mas de modo contrário ao OCP, forçando a manutenção da sílaba. Para a aplicação do processo, Oliveira (2012) apresenta a seguinte hierarquia (que vai de favorecimento a desfavorecimento): sílaba fraca $>$ acento lexical $>$ acento principal.

Tendo em vista os resultados da queda de sílaba na literatura e a combinação de acentos da primeira e segunda palavras, foram propostos 8 fatores para a variável Métrica: ${ }^{16}$

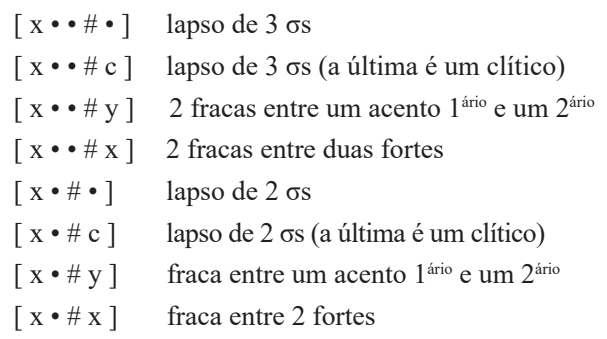

A otimização do ritmo depende de como o grau de proeminência das sílabas é entendido. Leal (2012) assume a seguinte hierarquia (do mais forte ao mais fraco): acento primário $>$ acento secundário $>$ clítico $=$ sílaba fraca. Nessa ordenação de proeminências, entende-se que o clítico fonológico é tão fraco quanto uma sílaba fraca (não clítica), e o esperado é que as sequências $[\mathrm{x} \bullet \# \mathrm{x}],[\mathrm{x} \bullet \# \mathrm{y}],[\mathrm{x} \bullet \# \bullet$ ] e [ $\mathrm{x} \bullet \# \mathrm{c}]$, ao sofrerem apagamento, tornem-se sequências ótimas ritmicamente, pois os resultados serão $[\mathrm{x} \bullet \# \mathrm{x}],[\mathrm{x} \bullet \# \mathrm{y}],[\mathrm{x} \# \bullet][\mathrm{x} \# \mathrm{c}]$, respectivamente.

${ }^{16}$ Nos dados a seguir, os sinais ' e , indicam acentos primário e secundário, respectivamente. Nas grades métricas, a sílaba forte está representada por $\mathrm{x}$, a fraca por $\bullet, \mathrm{y}$ indica acento secundário $\mathrm{e}$ c representa um clítico fonológico. 
As sequências $[\mathrm{x} \cdot * \bullet \cdot]$ e $[\mathrm{x} \cdot \cdots \mathrm{z}$ ], se sofrerem apagamento, melhoram ritmicamente (pois em vez de 3 sílabas fracas, passam a ter apenas 2), mas não são consideradas ótimas. Finalmente, as sequências $[\mathrm{x} \bullet \# \mathrm{x}] \mathrm{e}[\mathrm{x} \bullet \# \mathrm{y}]$, se sofrerem a queda de sílaba, criam contextos de encontro acentual. A hipótese, neste caso, é que a queda de sílaba tenderá a ser evitada, já que são criados contextos de encontros de acento.

A terceira variável é a Prosódia, definida a partir dos resultados de Tenani (2002), Battisti (2004), Pavezi (2006), Leal (2006) e Simioni e Amaral (2011). A hipótese para este grupo de fatores é que há variação de queda de sílaba em todos os constituintes prosódicos, isto é, nenhum deles bloqueia o processo. Outra hipótese é que há uma maior propensão ao apagamento no nível de frase fonológica, com base nos estudos de Battisti (2004), Pavezi (2006), Leal (2006) e Simioni e Amaral (2011). A questão a ser analisada é se a queda de sílaba é um fenômeno puramente fonológico ou se leva em conta informações de outros componentes gramaticais (a sintaxe, neste caso), seguindo-se a hierarquia prosódica de Nespor e Vogel (1986). Em linhas gerais, a hierarquia prosódica é uma teoria de interface entre a fonologia com outros níveis da gramática. Uma vez que a queda de sílaba é um processo de sândi externo (acontece em níveis acima da palavra), são três os níveis prosódicos analisados:

- Grupo Clítico (C): Dá-se a partir do mapeamento entre o componente fonológico e o morfossintático.

- Domínio: é uma palavra fonológica que contenha uma palavra independente (ou seja, não clítica) mais quaisquer ws adjacentes que contenham:

- i) um clítico direcional (ou seja, que pode estar só à esquerda ou só a direita de uma palavra fonológica); ou

- ii) um clítico propriamente dito (que pode estar ou à direita ou à esquerda de uma palavra fonológica), de tal forma que não haja nenhuma palavra independente (não clítica) possível, com o qual partilhe mais elementos de uma categoria.

Grosso modo, pode-se entender um Grupo Clítico como um conjunto formado de uma palavra independente e de um clítico. (Consultar o Capítulo 5 de Nespor e Vogel 1986 para detalhamento.)

- Frase fonológica $(\phi)$ : interface entre a fonologia e a sintaxe.

- Domínio: um $\mathrm{C}$ que contenha um núcleo lexical $(\mathrm{X})$ e todos os Cs de seu lado não recursivo ${ }^{17}$ até o $\mathrm{C}$ que contenha um outro núcleo fora da projeção máxima de X. De modo geral, pode-

${ }^{17}$ O lado recursivo de uma língua é a direção em que novos constituintes são inseridos. Assim, o lado recursivo do português é direito; seu lado não recursivo é o esquerdo. 
se dizer que esse constituinte fonológico se assemelha a um sintagma (mas cf. Capítulo 6 de Nespor e Vogel 1986).

- $\quad$ Frase entonacional (I): o mapeamento entre a fonologia e informações semânticas, sintáticas ou de performance (como a taxa de elocução, o tamanho da sentença, etc). De certa forma, a frase entonacional se aproxima a uma sentença (novamente, refiro o leitor a Nespor e Vogel 1986, Capítulo 7).

A seguir, estão as variantes da variável Prosódia:

entre Cs (e dentro de $\phi)$ entre $\phi s$ entre Is foi do la(DO) ] C [ DO prefeito, né? para depois vir para a cida(DE) $] \phi[$ DE novo cinco par(TES). ] I [ TUdo rosa

Em (28), o contexto de queda de sílaba /do + do/ está separado por uma fronteira de grupo clítico - ainda, esse contexto está dentro de uma mesma frase fonológica [do la(DO) DO prefeito] $\phi$; em (29), há uma fronteira de frase fonológica entre os contextos /de + de/; e, em (30), o contexto segmental /do + do/ está entre sentenças, isto é, entre duas frases entonacionais. A hipótese para esta variável é que há uma tendência à queda de sílaba em (29), e nenhum nível bloqueia o processo.

A quarta variável diz respeito ao Número de Sílabas da palavra sujeita à queda. O tamanho fonológico tem um efeito na aplicação de regras fonológicas, como mostram Sandalo e Truckenbrodt (2002), analisando a retração de acento no português brasileiro. As autoras verificaram que este processo fonológico é favorecido em frases fonológicas que tenham uma mesma extensão. Tenani (2002) encontrou resultados que apontam que enunciados maiores favorecem a haplologia.

Para este grupo de fatores, a hipótese é que a aplicação de queda de sílaba é proporcional ao tamanho da palavra: quanto maior a palavra, maior é a taxa de aplicação da queda de sílaba. As variantes estão apresentadas abaixo:

$\begin{array}{ll}\text { duas sílabas } & 2 \sigma \mathrm{s} \\ \text { três sílabas } & 3 \sigma \mathrm{s} \\ 4 \text { sílabas ou mais } & 4 \sigma \mathrm{s} \text { ou mais }\end{array}$

... no la(DO) DA santa cruz

... do brinque(DO), NÉ?

... o que que tá acontecen(DO), NÉ?

No exemplo (31), a palavra sujeita a apagamento é lado, que tem 2 sílabas; em (32), brinquedo é a palavra que pode sofrer o processo e constitui-se de 3 sílabas; e, em (33), acontecendo contém 5 sílabas. Assim, a hipótese é que a probabilidade de a queda de sílaba ser aplicada é maior em (33), já que acontecendo possui 5 sílabas. $^{18}$

${ }^{18}$ Vale ressaltar que o Número de Sílabas foi contado dentro da palavra fonológica (cf. Capítulo 4 em Nespor e Vogel 1986). Se o item lexical é certamente, por exemplo, há 2 acentos lexicais e, portanto, 2 palavras fonológicas ['certa] $\omega$ e ['mente] $\omega$. 
A quinta variável linguística é Frequência de Uso de Palavras, e a hipótese levantada é que a tendência de aplicação da queda de sílaba é proporcional à produtividade da palavra sujeita ao apagamento, isto é, palavras mais frequentes têm uma tendência à queda, com base em exemplos como apresentado a seguir: ${ }^{19}$

$$
\begin{array}{lll}
\text { cenTRO DO caos } & > & \text { cen(TRO) DO caos } \\
\text { coenTRO DO caldo } & > & \text { coen(TRO) DO caldo }
\end{array}
$$

Nos exemplos (34) e (35), o contexto segmental é o mesmo, /tro + do/ e a hipótese para esta variável é que haja uma maior propensão à queda de sílaba em (34), já que e a palavra sujeita ao apagamento centro é mais frequente do que coentro, apresentada em (35).

A análise de frequência de palavras foi feita em relação à frequência de tokens (em oposição à de types) ${ }^{20}$ porque o intuito é capturar o fato de uma palavra ser ou não sujeita à queda, a depender de sua frequência - e não relacionar a queda de sílaba a um determinado padrão; desse modo, informações específicas dos segmentos poderiam ser perdidas (como foi dito na seção 2, o contexto segmental é o que define o processo de queda de sílaba - cf. Leal 2006, 2007, 2012, 2018). Com o método de contagem de frequência definido (tokens), um problema que se coloca é que o número de ocorrências no nosso corpus (5628) é muito pequeno se considerarmos a língua portuguesa de maneira geral. A fim de poder representar as frequências do português como um todo, foram utilizadas as frequências de tokens do Avaliação Sonora do Português Atual (ASPA). ${ }^{21,22}$

O cálculo para se delimitar os três fatores foi feito seguindo-se a metodologia empregada em Françozo et al. (2002) que, analisando um corpus com aproximadamente 1 bilhão e 420 milhões de ocorrências de palavras, estabeleceu as seguintes faixas de frequência: (i) palavras muito frequentes: mais de 100 ocorrências por milhão; (ii) palavras pouco frequentes: entre 5 e 50 ocorrências por milhão; e (iii) palavras raras: menos de 1 ocorrência por milhão.

Assim, as variantes foram calculadas a partir das frequências de Françozo et al. (2002) e foram adaptadas ao ASPA, que conta com 607.392 types e um total de 228.766.402 tokens.

Os fatores para a variável Frequência de Uso de Palavras são os seguintes: ${ }^{23}$

${ }^{19}$ Agradeço ao professor Jairo Nunes por ter me apontado essa possibilidade de análise.

${ }^{20}$ Bybee (2010, p. 10-11) explica que a frequência de token se refere à ocorrência de uma unidade em um determinado texto, isto é, concerne à frequência que uma determinada palavra aparece num dado texto; quanto à frequência de type, está relacionada à frequência de um dado padrão.

${ }^{21}$ O projeto ASPA foi elaborado por Thaïs Cristófaro Silva, em parceria com Leonardo Almeida (CPDEE-UFMG), Raquel Fontes-Martins (Poslin-FALE-UFMG), César Reis (Labfon-FALE-UFMG), Hani Camille Yehia (Cefala-DELT-UFMG), Rafael Laboissiere (MaxPlank Institute-Germany) e Tony Sardinha (PUCSP). Cf. site do projeto http://www.projetoaspa.org/.

${ }^{22}$ Agradeço à professoraThaïs Cristófaro Silva por nos fornecer o acesso ao buscador de frequência do corpus ASPA.

${ }^{23}$ Houve 90 tokens que não entraram nessa variável, o que totalizou, ao final, 5538 dados analisados. As exclusões são neologismos (como aborrescente), nomes próprios (Windows, Zepe), derivados de nomes próprios (capivariana), palavras em inglês (diesel, diet), entradas com 2 palavras (são paulino). Para a maioria dos nomes próprios (como Campinas, Roberto, Diego) encontrados no corpus deste trabalho, há entradas no ASPA, e entraram na contagem. 
Na próxima seção, estão as variáveis analisadas, comparando-se os resultados das cidades de Capivari e Campinas.

\section{OS RESULTADOS: COMPARAÇÃO ENTRE AS DUAS CIDADES}

Nesta seção, o intuito é verificar se a queda de sílaba tem as mesmas características em Capivari e Campinas ou se há regras diferentes para a aplicação do processo.

A Tabela a seguir apresenta a distribuição geral dos dados:

Tabela 1. Distribuição geral dos dados nas rodadas de Capivari, de Campinas e o total

\begin{tabular}{|c|c|c|c|c|c|c|}
\hline Ocorrência & \multicolumn{2}{|c|}{ Capivari } & \multicolumn{2}{c|}{ Campinas } & \multicolumn{2}{c|}{ Total } \\
\hline aplicação & 449 & $17,3 \%$ & 737 & $24,3 \%$ & 1186 & $21,1 \%$ \\
\hline não aplicação & 2150 & $82,7 \%$ & 2292 & $75,7 \%$ & 4442 & $78,9 \%$ \\
\hline Total & 2599 & & 3029 & & 5628 & \\
\hline
\end{tabular}

Como se observa na Tabela 1 , o total de dados para análise foi 5628, com $21,1 \%$ de aplicação de queda de sílaba $(\mathrm{N}=1186 / 5628)$; para Capivari, houve $17,3 \%$ de aplicação, com N=449/2599 e, para Campinas a taxa foi $24,3 \%$, com $\mathrm{N}=737 / 3029 .^{24}$

As comparações dos resultados das variáveis internas estão nas subseções a seguir, apresentadas segundo a igualdade (cf. 4.1), a semelhança (ver 4.2) e a diferença (cf. 4.3) nas duas cidades.

\section{Variável igual}

Uma variável linguística que revelou resultados iguais nas duas cidades foi Prosódia. As hipóteses formuladas foram que não há um nível que bloqueie o

${ }^{24}$ Esse resultado de a queda de sílaba ter uma maior aplicação em Capivari do que em Campinas foi de encontro à hipótese para a variável Cidades (cf. Leal 2012): o processo seria mais aplicado na cidade de Capivari, pois há mais contextos de aplicação (com base nos resultados de Leal 2006) do que em outros dialetos (cf. Alkmim e Gomes 1982, Bisol 2000, Tenani 2002, Battisti 2004, 2005, Pavezi 2006, Leal 2006, 2007, 2012, Mendes 2009, Simioni e Amaral 2011, Oliveira 2012, 2013, Oliveira e Paz 2013, Paz 2013). Ao analisar cada um dos informantes, foi verificado que houve idiossincrasias de 9 pessoas que, ou aplicaram muito, ou desfavoreceram muito a queda de sílaba: houve 5 informantes que favoreceram excessivamente o processo e, dentre eles, 3 são campineiros - isto é, um grande favorecimento em Campinas. Os outros 4 informantes desfavoreceram a queda de sílaba, e 3 são capivarianos - ou seja, grande desfavorecimento em Capivari. 
processo e que o nível com uma maior tendência ao apagamento é o da frase fonológica. A Tabela 2 abaixo apresenta os resultados dessa variável:

Tabela 2. Comparação dos resultados da variável Prosódia

\begin{tabular}{|c|c|c|c|c|c|c|}
\hline Contexto & Capivari & $\%$ & p.r. & Campinas & $\%$ & p.r. \\
\hline entre Is & $76 / 814$ & 9.34 & 0.444 & $126 / 880$ & 14.32 & 0.45 \\
\hline entre $\phi$ s & $150 / 624$ & 24.04 & 0.571 & $208 / 689$ & 30.19 & 0.552 \\
\hline $\begin{array}{c}\text { entre Cs (dentro } \\
\text { de } \phi)\end{array}$ & $223 / 1161$ & 19.21 & 0.501 & $403 / 1460$ & 27.6 & 0.505 \\
\hline Total & $449 / 2599$ & 17.28 & & $737 / 3029$ & 24.33 & \\
\hline
\end{tabular}

Para facilitar a visualização dos resultados, os pesos relativos estão apresentados a seguir em formato de gráfico: ${ }^{25}$

\section{Gráfico 1. Comparação dos resultados da variável Prosódia}

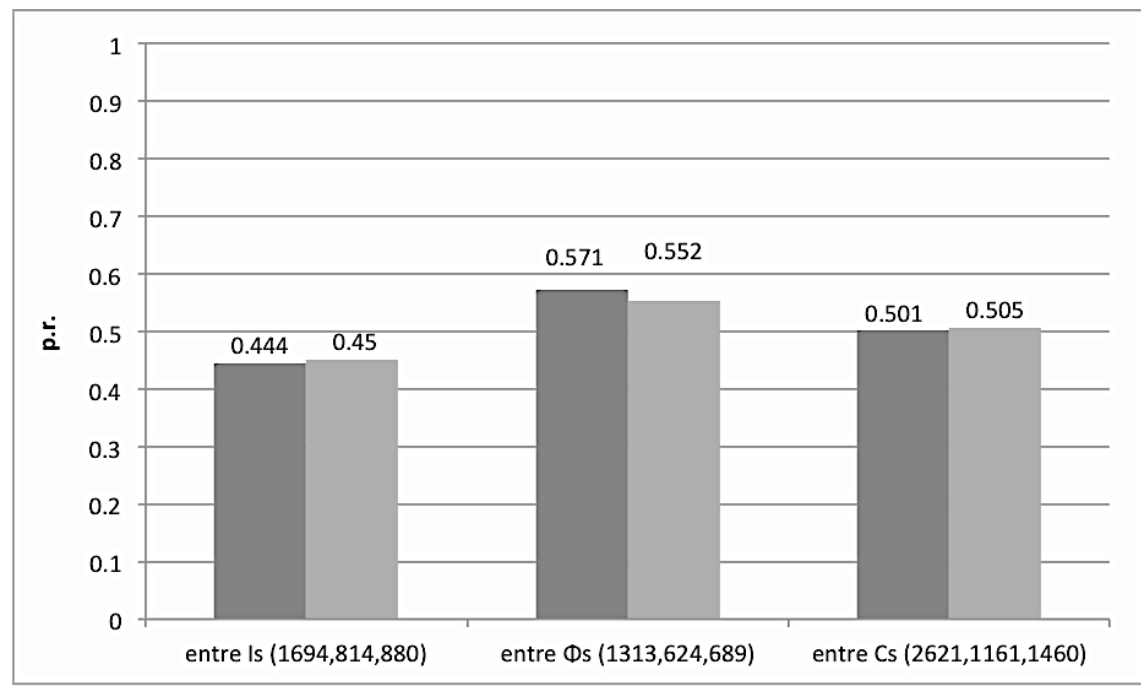

Capivari

Campinas

Como se vê no Gráfico 1, os resultados para Prosódia foram muito parecidos nas duas cidades: entre sentenças, há um leve desfavorecimento da queda de sílaba (fronteira entre frase entonacional); há um leve favorecimento do processo entre frases fonológicas, o que corrobora a hipótese inicial; e se a primeira e a segunda

${ }^{25}$ Nos parênteses dos Gráficos, estão apresentados os números de tokens das variantes, na seguinte ordem: da rodada Geral, da rodada de Capivari e da rodada de Campinas. Por exemplo, no fator entre Is, os números indicam que houve 1694 dados na rodada Geral, 814 tokens em Capivari e 880 em Campinas. 
sílabas do contexto segmental estiverem entre dois grupos clíticos, há uma neutralidade. Ainda, foi corroborada também a hipótese de que não há bloqueio de queda de sílaba em nenhum nível prosódico.

Assim, concluímos que o efeito da hierarquia prosódica na queda de sílaba em Capivari e em Campinas é a mesma.

\section{Variáveis semelhantes}

A hipótese levantada para a variável Estrutura Silábica foi que pode haver variação de queda de sílaba com estruturas silábicas diferentes de $\mathrm{CV}$, e que, quanto mais leves as sílabas, maior a aplicação do processo. No gráfico abaixo estão frequências e proporções obtidas nas rodadas:

Tabela 3. Comparação dos resultados da variável Estrutura Silábica

\begin{tabular}{|c|c|c|c|c|c|c|}
\hline Contexto & Capivari & $\%$ & p.r. & Campinas & $\%$ & p.r. \\
\hline $\mathrm{CV}+\mathrm{CV}$ & $306 / 1613$ & 18.97 & 0.542 & $477 / 1772$ & 26.92 & 0.506 \\
\hline $\mathrm{CVC}+\mathrm{CVC}$ & $3 / 32$ & 9.38 & 0.36 & $5 / 41$ & 12.2 & 0.482 \\
\hline $\mathrm{CCV}+\mathrm{CCV}$ & $1 / 4$ & 25 & 0.406 & $2 / 4$ & 50 & 0.935 \\
\hline $\mathrm{CV}+\mathrm{o}$ & $91 / 580$ & 15.69 & 0.485 & $160 / 735$ & 21.77 & 0.586 \\
\hline $\mathrm{CVC}+\mathrm{o}$ & $18 / 196$ & 9.18 & 0.295 & $20 / 228$ & 8.77 & 0.287 \\
\hline $\mathrm{CCV}+\mathrm{o}$ & $24 / 135$ & 17.78 & 0.479 & $58 / 175$ & 33.14 & 0.5 \\
\hline o + o & $6 / 39$ & 15.38 & 0.31 & $15 / 74$ & 20.27 & 0.213 \\
\hline total & $449 / 2599$ & 17.28 & & $737 / 3029$ & 24.33 & \\
\hline
\end{tabular}

Os resultados dos pesos relativos estão apresentados no Gráfico a seguir:

\section{Gráfico 2. Comparação dos resultados da variável Estrutura Silábica}

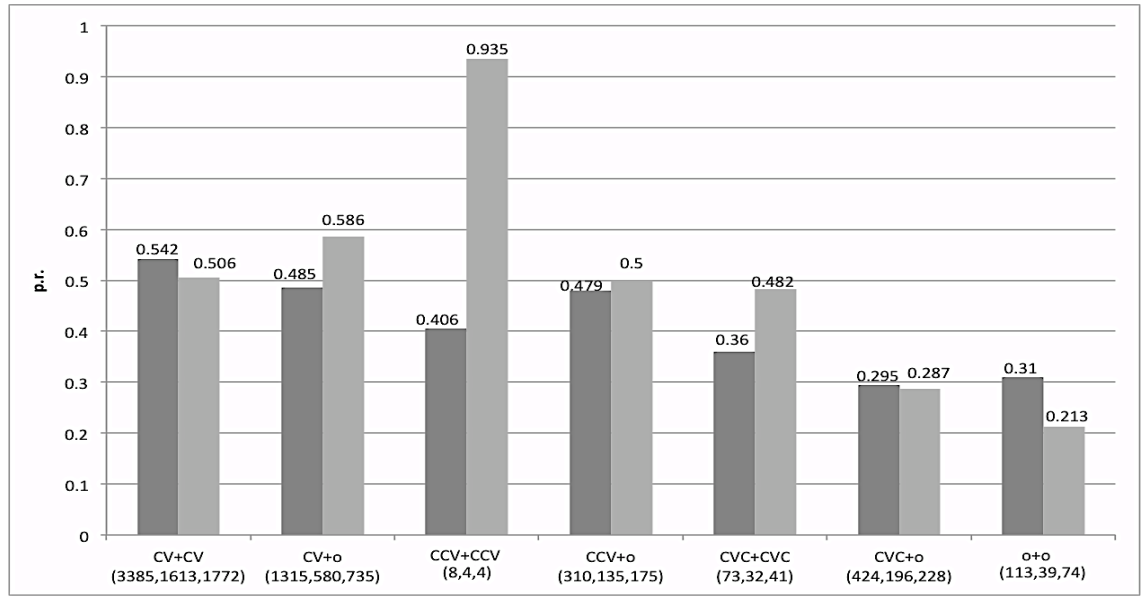

Capivari

Campinas 
Como se observa no Gráfico 2, contextos com duas sílabas simples (cf. $\mathrm{CV}+\mathrm{CV}$ ) têm comportamentos um pouco diferentes nas cidades: há um leve favorecimento em Capivari e neutralidade em Campinas; para sequências em que há uma sílaba simples seguida de outros tipos de estruturas, isto é, estruturas diferentes de $\mathrm{CV}$ (ver $\mathrm{CV}+$ o no gráfico), ocorre o contrário: há um favorecimento em Campinas e neutralidade em Capivari. Em um contexto com uma sílaba de ataque ramificado seguida de outros tipos de estruturas (que não sejam CCV cf. $\mathrm{CCV}+\mathrm{o}$ no gráfico), o processo é neutro nas duas cidades; em sequências de sílabas sujeitas à queda que tenham coda ramificada e seguidas de outros tipos de estruturas, que sejam diferentes de $\mathrm{CVC}$ (ver $\mathrm{CVC}+\mathrm{o}$ no gráfico), os pesos relativos são muito parecidos, indicando um desfavorecimento do processo. Assim, podemos interpretar que, estes dois contextos $(\mathrm{CCV}+\mathrm{o}$ e $\mathrm{CVC}+\mathrm{o})$ são iguais nas duas cidades.

Com relação às sequências em que há ataque ramificado em ambas as sílabas (cf. contexto $\mathrm{CCV}+\mathrm{CCV}$ ) e também estruturas com coda nas duas sílabas (ver $\mathrm{CVC}+\mathrm{CVC}$ ), os resultados são inconclusivos, já que o número de tokens foi baixo (a maior quantidade nestes casos foi 73 dados).

Assim, hipótese inicial foi parcialmente confirmada para sílabas com coda: de fato, essas estruturas desfavorecem o processo em ambos os dialetos; mas somente se estiverem na primeira posição, sem necessidade de o contexto ter as duas sílabas com estrutura CVC - observando-se que, para contextos CVC $+\mathrm{CVC}$, o resultado foi inconclusivo, devido ao baixo número de tokens. Dessa forma, pode-se interpretar que a igualdade das estruturas das sílabas não é importante para o processo, mas sim a estrutura da primeira sílaba. ${ }^{26}$

Outra hipótese para esta variável foi que quanto mais leve fosse a sílaba sujeita ao apagamento, maior seria a tendência à queda; entretanto, sílabas leves (na primeira posição) ou favorecem somente em Capivari, ou são neutras ao processo em Campinas. Finalmente, sílabas com ataque ramificado (em primeira posição) são neutras - não tínhamos uma hipótese, mas levantamos a seguinte pergunta: a segunda consoante do ataque "atrapalha" a queda de sílaba ou é inerte? Pudemos verificar que o comportamento de estruturas CCV é semelhante a CV, isto é, estruturas CCV são neutras ao processo - a segunda consoante do ataque não "atrapalha" a queda de sílaba.

Para a variável Métrica, a hipótese que levantamos está relacionada à sequência dos acentos da primeira e da segunda palavras: o resultado de queda de sílaba deve ter uma tendência ao PAR, ou seja, a aplicação do processo deverá fazer com que os acentos fortes e fracos se alternem.

Tendo em vista a combinação de acentos da primeira e segunda palavras, os resultados foram os seguintes:

${ }^{26}$ Os resultados para o contexto vocálico de Leal (2012: 231) também apontam que o OCP parece não atuar na queda de sílaba, pois o ponto de $\mathrm{C}$ da vogal sujeita ao apagamento parece ser mais relevante. 
Tabela 4. Comparação dos resultados da variável Métrica

\begin{tabular}{|c|c|c|c|c|c|c|}
\hline Contexto & Capivari & $\%$ & p.r. & Campinas & $\%$ & p.r. \\
\hline$[\mathrm{x} \cdot * \# \cdot]$ & $5 / 11$ & 45.45 & 0.614 & $4 / 15$ & 26.67 & 0.78 \\
\hline$[\mathrm{x} \cdot * \# \mathrm{c}]$ & $13 / 38$ & 34.21 & 0.687 & $18 / 55$ & 32.73 & 0.815 \\
\hline$[\mathrm{x} \cdot * \# \mathrm{y}]$ & $0 / 3$ & 0 & n.a. & $1 / 3$ & 33.33 & 0.956 \\
\hline$[\mathrm{x} \cdot \# \mathrm{x}]$ & $4 / 32$ & 12.5 & 0.469 & $6 / 41$ & 14.63 & 0.552 \\
\hline$[\mathrm{x} \bullet \# \cdot]$ & $70 / 378$ & 18.52 & 0.548 & $99 / 441$ & 22.45 & 0.472 \\
\hline$[\mathrm{x} \bullet \# \mathrm{c}]$ & $218 / 894$ & 24.38 & 0.61 & $406 / 1142$ & 35.55 & 0.655 \\
\hline$[\mathrm{x} \bullet \# \mathrm{y}]$ & $26 / 107$ & 24.3 & 0.67 & $30 / 111$ & 27.03 & 0.613 \\
\hline$[\mathrm{x} \bullet \# \mathrm{x}]$ & $113 / 1136$ & 9.95 & 0.376 & $173 / 1221$ & 14.17 & 0.332 \\
\hline Total & $449 / 2599$ & 17.28 & & $737 / 3029$ & 24.33 & \\
\hline
\end{tabular}

Os pesos relativos estão apresentados no Gráfico a seguir:

\section{Gráfico 3. Comparação dos resultados da variável Métrica}

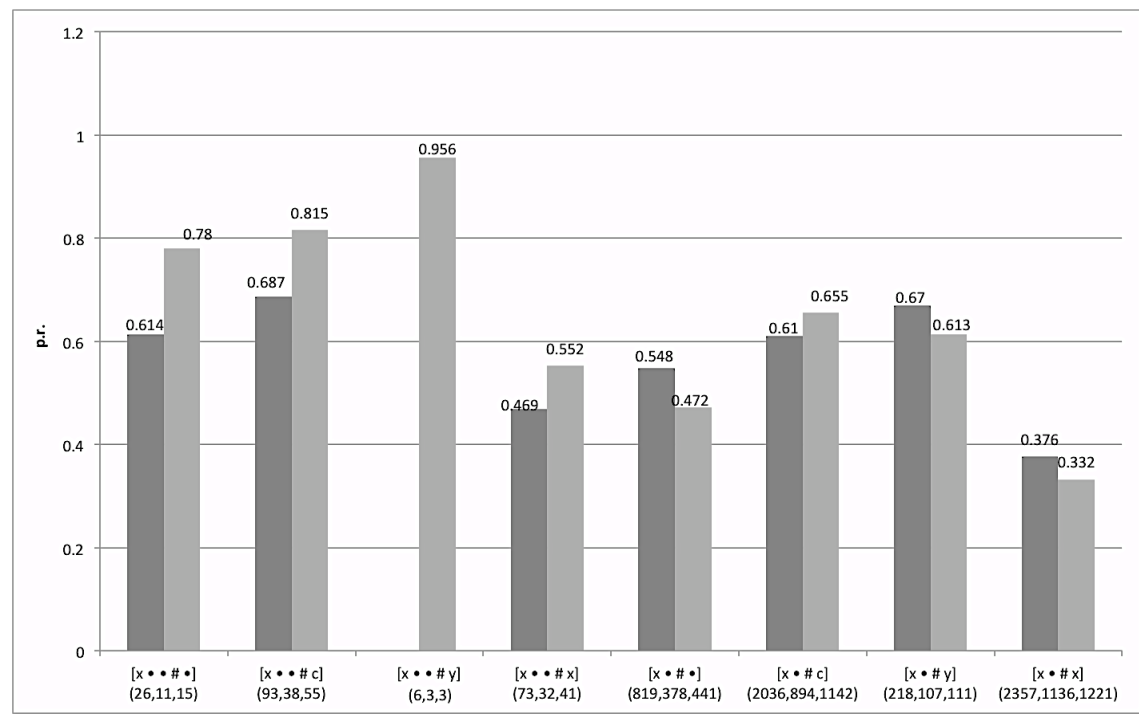

Capivari

Campinas

Houve baixo número de ocorrências de fatores em que a primeira palavra tivesse um acento forte seguido de um lapso de duas sílabas [ $\mathrm{x} \bullet \bullet$ ], com um total de somente 84 dátilos em Capivari e 114 em Campinas. ${ }^{27}$ Para os casos com

${ }^{27}$ Para contextos de um dátilo seguido de uma sílaba fraca ( $\mathrm{cf}$. contexto $\mathrm{x} \bullet \bullet \# \bullet$ ), houve 11 ocorrências em Capivari e 15 em Campinas; para dátilos seguidos de clítico (ver x • • \# c), foram 38 em Capivari e 55 em Campinas; nos ambientes de um dátilo seguido de uma sílaba com acento secundário 
um acento primário seguido de uma fraca $[\mathrm{x} \bullet$ ], consideramos que os resultados foram semelhantes nas duas cidades: se seguidas de clíticos [ $\mathrm{x}(\bullet)$ \# c ] ou de acento secundário [ $\mathrm{x}(\bullet)$ \# y ], há um favorecimento da queda de sílaba. ${ }^{28}$ As sequências em que a aplicação da queda de sílaba resulta em choque de acento [ $\mathrm{x}(\bullet) \# \mathrm{x}$ ] desfavorecem o processo. Assim, a aplicação da queda de sílaba com um resultado rítmico ruim (de acordo com o PAR) não é bloqueado, mas sim desfavorecido (com pesos relativos de p.r. $=0,376$ para Capivari e p.r. $=0,332$ para Campinas).

Portanto, os resultados da variável Métrica podem ser considerados semelhantes nas duas cidades.

Ainda, é importante comparar os resultados rítmicos de aplicação do processo em $\quad[\mathrm{x} \# \mathrm{x}]$ vs. $[\mathrm{x} \# \mathrm{y}]$ e em $[\mathrm{x} \# \mathrm{c}]$ vs. $[\mathrm{x} \# \bullet \cdot$. No primeiro par, a aplicação de queda de sílaba resulta em choque de acentos primários $[\mathrm{x} \# \mathrm{x}]$, ocasionando desfavorecimento. No entanto, o mesmo não ocorreu com o choque de um acento primário seguido de um secundário [x \# y], visto que a queda de sílaba foi favorecida nesse contexto. No segundo par, após o apagamento da sílaba, contextos com uma sílaba forte seguida de uma fraca [x \# • $]$ são favorecidos em Capivari, assim como no contexto [x \# c], também nessa cidade. Entretanto, a estrutura $[\mathrm{x} \# \cdot$ ] é neutra em Campinas, e o esperado era que o comportamento de uma sílaba fraca deveria ser similar ao de um clítico - considerando-se que clíticos são unidades fonológicas desprovidas de acento, tanto quanto as sílaba fracas. Em outras palavras, o esperado era que contextos em que uma sílaba forte é seguida de outra fraca, seja $[\mathrm{x} \# \bullet$ ou $[\mathrm{x} \# \mathrm{c}]$, deveriam ser linguisticamente semelhantes, o que não aconteceu.

E esses resultados podem ser interpretados de dois modos: (i) ou a hierarquia de acentos deve ser revista, considerando que há apenas uma acento forte (o primário) e todos os outros graus são fracos; (ii) ou a aplicação de queda de sílaba leva em conta apenas o acento primário, desprezando igualmente o acento secundário, o clítico fonológico e a sílaba fraca.

\section{Variáveis diferentes}

Com relação ao Número de Sílabas, essa variável não foi selecionada em Campinas, ou seja, o tamanho fonológico parece não ser importante na implementação da regra nesta cidade; ainda, podemos interpretar que o efeito do tamanho da palavra é diferente nas duas cidades (importa para Capivari e não importa para Campinas).

A hipótese levantada foi que, quanto maior fosse a palavra, maior seria a tendência à queda. Dos resultados para Capivari, pudemos observar que dissílabos

(cf. $\mathrm{x} \cdot$ - \# y), houve 3 casos em Capivari e 3 em Campinas; por fim, para dátilos seguidos de uma sílaba forte (ver x • * x x), foram 32 contextos em Capivari e 41 em Campinas. Esses casos devem ser analisados qualitativamente, o que será feito em outro trabalho. Agradeço à professora Luciani Tenani por me apontar esse fato.

${ }^{28}$ Para contextos $[\mathrm{x} \cdot \# \mathrm{c}$ ] p=0,61 em Capivari e $\mathrm{p}=0,655$ em Campinas. Com relação aos casos $[\mathrm{x} \bullet \# \mathrm{y}]$, os pesos relativos foram $\mathrm{p}=0,67 \mathrm{e} \mathrm{p}=0,613$, para Capivari e Campinas, respectivamente. 
desfavorecem o processo, trissílabos parecem ser inertes e palavras que tenham 4 sílabas ou mais favorecem o processo. Assim, os resultados para essa variável corroboram os de Tenani (2002) para a haplologia, pois é mais aplicada em enunciados de tamanhos maiores.

Concluímos que o favorecimento de queda de sílaba aumenta à medida que a palavra se torna mais extensa, como se observa na Tabela 5 e no Gráfico 4 a seguir (para Capivari):

Tabela 5. Resultados da variável Número de Sílabas em Capivari

\begin{tabular}{|c|c|c|c|}
\hline Contexto & Capivari & $\%$ & p.r. \\
\hline $2 \sigma s$ & $241 / 1508$ & 16 & 0.46 \\
\hline $3 \sigma s$ & $124 / 717$ & 17.3 & 0.519 \\
\hline 4 бs ou mais & $84 / 374$ & 22.5 & 0.624 \\
\hline Total & $449 / 2599$ & 17.3 & \\
\hline
\end{tabular}

Gráfico 4. Resultados da variável Número de Sílabas em Capivari

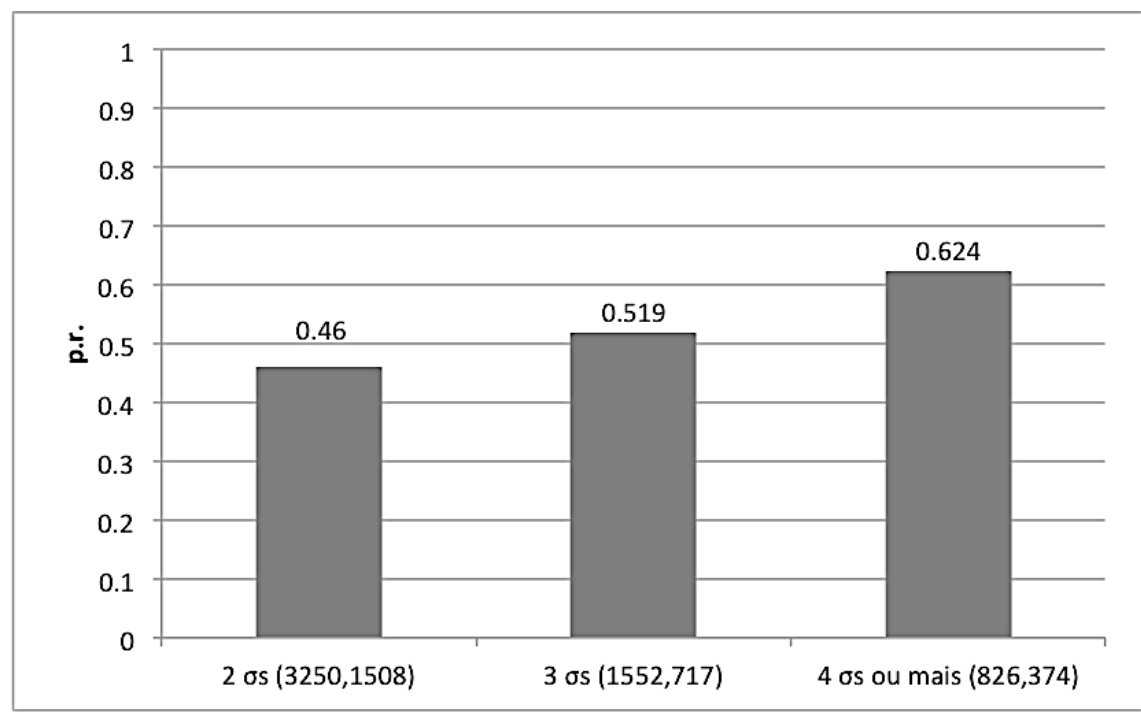

Capivari

Para Número de Sílabas, consideramos que os resultados foram diferentes nas duas cidades, pois este grupo de fatores foi selecionado somente em Capivari, ou seja, o tamanho da palavra sujeita à queda não interfere na queda de sílaba em Campinas). Os resultados para Capivari corroboraram a hipótese inicial, visto que palavras com 4 sílabas ou mais favorecem o processo, com p.r. $=0,624$; palavras com 3 sílabas são neutras (p.r.=0,519); e palavras com duas sílabas desfavorecem o processo (p.r. $=0,46)$. 
A última variável linguística que apresentou diferenças entre Capivari e Campinas é Frequência de Uso de Palavras, já que esta variável não foi selecionada na rodada de Capivari - e a interpretação foi que não é importante se a palavra é frequente ou rara nessa cidade. Então, os resultados desta variável apresentam diferença entre os campineiros e os capivarianos.

A hipótese foi que quanto mais frequente fosse a palavra, maior seria a tendência ao apagamento. Os resultados de Campinas apontam que se a palavra sujeita ao apagamento tiver uma frequência alta de uso, o processo é inerte, e que palavras de frequência média de uso favorecem a aplicação. Para palavras de baixa frequência de uso, há um desfavorecimento do processo, e este é o único fator que corrobora a hipótese inicial.

Tabela 6. Resultados da variável Frequência de Uso de Palavras em Campinas

\begin{tabular}{|c|c|c|c|}
\hline Contexto & Campinas & $\%$ & p.r. \\
\hline alta & $385 / 1570$ & 24.52 & 0.502 \\
\hline média & $164 / 519$ & 31.6 & 0.559 \\
\hline baixa & $182 / 909$ & 20.02 & 0.463 \\
\hline Total & $731 / 2998$ & 24.38 & \\
\hline
\end{tabular}

Gráfico 5. Resultados da variável Frequência de Uso de Palavras em Campinas

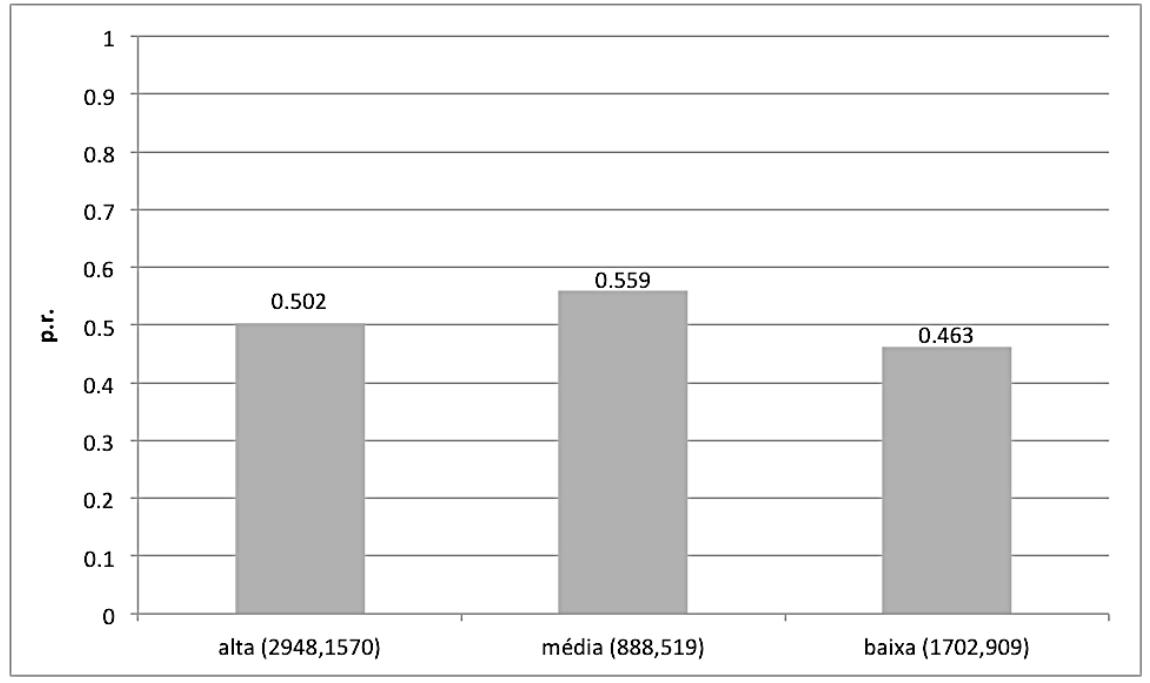

Campinas

No que concerne à Frequência de Uso da palavra sujeita ao apagamento, os resultados apontam que aquelas que têm uma frequência média (de 10.451 
a 20.899 ocorrências no ASPA) favorecem o processo (p.r.=0,559), enquanto que palavras de alta frequência (mais de 20.900 ocorrências no ASPA) parecem ser neutras (p.r. $=0,502)$, e palavras de baixa frequência (com menos de 10.450 ocorrências no ASPA) desfavorecem o processo (p.r. $=0,463$ ).

Pode-se depreender então que o efeito de frequências de palavras é diferente nas duas cidades.

\section{CONCLUSÃO}

O principal objetivo neste artigo foi verificar se a implementação da queda de sílaba é igual ou diferente nos dialetos de Capivari e de Campinas, com relação a variáveis internas. Com esse fim, três interpretações foram consideradas nas comparações dos grupos de fatores (cf. seção 4): variáveis iguais (tendências e pesos relativos são iguais nas duas cidades); variáveis semelhantes (tendências iguais, mas com pesos relativos diferentes); e variáveis diferentes (tendências distintas nas duas cidades e, portanto, os pesos relativos também são diferentes; ou ainda, se uma variável foi selecionada numa cidade e não foi em outra).

Para a variável Estruturas das Sílabas do contexto de queda, houve variação com sílabas CCV na primeira posição, ou seja, não há bloqueio do processo com sílabas de ataque ramificado, resultado que vai de encontro aos de Alkmim e Gomes (1982), e corrobora Battisti (2004), Pavezi (2006) e Leal (2006). Foi verificado também que estruturas $\mathrm{CCV}$ parecem não interferir no processo, pois os resultados indicam uma neutralidade da queda de sílaba nesses contextos. Foi visto também que se, a primeira sílaba tiver coda $\mathrm{CVC}$, o processo é desfavorecido em ambas as cidades. Assim, conclui-se que, nesta variável, é a estrutura da sílaba sujeita à queda (e não a igualdade entre elas) que dita se há um maior ou menor favorecimento em ambas as cidades.

Da variável Métrica, houve um favorecimento nos contextos originais de uma sílaba forte seguida de uma fraca e de um clítico [ $\mathrm{x} \bullet \mathrm{A}$ ], e também de uma sílaba forte seguida de uma fraca e um acento secundário $[\mathrm{x} \cdot \# \mathrm{y}]$; houve neutralidade em contextos em que há uma sílaba forte seguida de duas fracas $[\mathrm{x} \bullet \# \bullet]$; e houve um desfavorecimento se o contexto original resultar em choque acentual depois da aplicação do processo $[\mathrm{x} \bullet \# \mathrm{x}]$. Os resultados foram considerados semelhantes nas duas cidades.

Com relação às variáveis Número de Sílabas e Frequência de Uso da Palavra Sujeita ao Apagamento, os resultados foram diferentes, já que cada uma dessas variáveis foi selecionada em apenas uma das cidades. O tamanho fonológico (variável Número de Sílabas) é importante na aplicação do processo em Capivari, mas não em Campinas. Naquela cidade, vimos que dissílabos desfavorecem (levemente) o processo, trissílabos são neutros e palavras de mais de quatro sílabas favorecem um pouco a queda de sílaba. Com base nestes resultados, interpretamos que a informação pode ser mais facilmente recuperada pelo ouvinte se a palavra sujeita à queda for maior em número de sílabas. 
A variável Frequência de Uso de Palavras sujeitas ao apagamento parece não importar no dialeto capivariano, enquanto que, no campineiro, há diferenças se é uma palavra de frequência média (que favorece o processo), de baixa frequência (desfavorecendo a queda de sílaba) ou de alta frequência (há uma neutralidade nesses casos).

Foi visto que o efeito da Prosódia é praticamente idêntico nas duas cidades: há uma neutralidade entre grupos clíticos, o processo é (levemente) inibido entre sentenças e é (levemente) favorecido na fronteira de duas frases fonológicas.

Como foi visto, a partir da comparação entre uma cidade que é atualmente um dos grandes polos urbanos do Brasil (Campinas) e outra cidade que é tipicamente interiorana (Capivari), puderam ser feitas inferências específicas quanto a comportamentos linguísticos nessas cidades.

Mas também foi possível depreender propriedades mais gerais, que podem contribuir a estudos fonológicos e linguísticos.

Para a hierarquia prosódica, houve um (leve) favorecimento da queda de sílaba no nível da frase fonológica em Campinas e em Capivari, o que corrobora as constatações relacionadas à haplologia para os dialetos de Porto Alegre (Battisti 2004), de São José do Rio Preto-SP (Pavezi 2006), de Capivari-SP (Leal 2006) e de Bagé-RS (Simioni e Amaral 2011). Desses trabalhos anteriores, é pertinente comparar essas cidades e observar, por exemplo, a localização delas, tomando-se como referência as cidades grandes do estado de São Paulo (Campinas) e do Rio Grande do Sul (a capital Porto Alegre): no interior de São Paulo, Campinas dista $50 \mathrm{~km}$ de Capivari (estão próximas); entre Campinas e São José do Rio Preto, são $350 \mathrm{~km}$ de distância. No estado do Rio Grande do Sul, Porto Alegre fica a $380 \mathrm{~km}$ de Bagé. E a distância que separa Campinas e Porto Alegre é de 1200 $\mathrm{km}$. Há certamente, outras diferenças entre essas cidades e dialetos, mas apenas observando as áreas em que se encontram essa cidades, é interessante notar que todas as autoras encontraram resultados em que a frase fonológica é o nível mais favorável à queda de sílaba. E são resultados importantes: apontam que a sintaxe deve ser levada em conta em trabalhos futuros, uma vez que a frase fonológica é um nível prosódico que resulta da interação entre a fonologia e constituintes sintáticos. Assim, seria interessante observar como os constituintes prosódicos atuam na queda de sílaba em outros dialetos - assim, uma aproximação seria verificar a relação entre a queda de sílaba e a fonologia/sintaxe no português brasileiro como um todo.

Outra constatação interessante está relacionada ao OCP: na variável Estrutura Silábica, os resultados apontaram que as características da primeira sílaba do contexto parecem ser mais importantes do que a igualdade entre as estruturas silábicas, ou seja, há aqui uma indicação de que o OCP parece não ser importante na aplicação do processo.

Os resultados da variável Métrica podem trazer contribuições a estudos sobre o PAR e sobre a hierarquia de acento. Como se observou, a aplicação de queda de sílaba produz resultados que apresentaram uma tendência ao PAR, já que, as proeminências acentuais geradas otimizaram o ritmo; interessantemente, em lugar de bloquear o processo, se o resultado da aplicação for um choque acentual, 
com duas sílabas fortes adjacentes, a queda de sílaba pode, ainda assim, ser implementada (houve desfavorecimento nesses casos, mas não bloqueio).

Esses resultados sobre o OCP e sobre o PAR podem contribuir à teoria fonológica, inseridos em questões relacionadas a universais linguísticos, à gramática universal. Na teoria gerativa, as línguas estão estruturadas por princípios e parâmetros (cf. Chomsky 1965), e os princípios chomskyanos são universais, no sentido de que todas as línguas têm as mesmas propriedades capturadas por eles, e não há línguas nas quais eles não se apliquem. No entanto, na fonologia gerativista, existe alguma variação: diferentemente da sintaxe, assume-se que na fonologia haja também regras (por exemplo, elisão, degeminação, ditongação), nem todas redutíveis a combinações paramétricas. Da mesma forma, os princípios fonológicos são mais flexíveis do que os sintáticos, já que podem agir ou não numa determinada língua, num dialeto - ou num processo fonológico. Assim, constatou-se que o PAR age na queda de sílaba, se se considerar que há uma otimização do ritmo no resultado da aplicação do processo, mas não há um rigor quanto a resultados de choques acentuais - não são bloqueados. Quanto ao OCP, é um princípio que parece não reger a queda de sílaba, pois a estrutura da primeira posição é mais importante.

No que diz respeito à hierarquia de acento, foram estudadas quatro proeminências, na seguinte ordenação: acento primário $>$ acento secundário $>$ clítico $=$ sílaba fraca . O comportamento desses elementos na queda de sílaba foi que há uma única proeminência, a sílaba forte, e todas as outras são fracas, resultados que foram interpretados de duas maneiras. Na primeira, a hierarquia acentual deve ser revista, pois pode-se considerar que apenas o acento primário é proeminente e que o acento secundário, o clítico e sílaba fraca não têm, igualmente, proeminência nenhuma. Na segunda interpretação, apenas o acento primário deve ser levado em consideração na queda de sílaba, enquanto que a proeminência do acento secundário e do clítico fonológico devem ser ignorados.

Por fim, pôde-se constatar que Capivari e Campinas têm regras diferentes de aplicação de queda de sílaba no que concerne aos efeitos de influências linguísticas.

\section{REFERÊNCIAS}

ALKMIM, T.M.; GOMES, C. A. 1982. Dois fenômenos de supressão de segmentos em limite de palavra. Ensaios de Linguística, 7: 43-51.

BATTISTI, E. 2004. Haplologia sintática e efeitos da economia. Organon (UFRGS), Porto Alegre RS, v. 18, n. 36, pp. 31-39.

BATTISTI, E. 2005. Haplologia no português do sul do Brasil: Porto Alegre. Letras de Hoje 40(3): 73-88.

BISOL, L. 2000. O troqueu silábico no sistema fonológico (Um adendo ao artigo de Plínio Barbosa). D.E.L.T.A. Vol.16, 2: 403-13. 
BOERSMA, P.; WEENINK, D. 2010. Praat: doing phonetics by computer (Versão 5.1.23). Disponível em: $<$ http://www.praat.org/>. Acesso em: 24 mai 2011.

BYBEE, J.L. 2010. Language, Usage and Cognition. Cambridge: Cambridge University Press.

CÂMARA, J.M. 1969. Problemas de Linguística Descritiva. Petrópolis: Vozes.

CHOMSKY, N. 1965. Aspects of the Theory of Syntax. Cambridge: The MIT Press

CLEMENTS, G.N.; HUME, E. 1995. The Internal Organization of Speech Sounds. J. Goldsmith (ed). The Handbook of Phonological Theory. Oxford: Basil Blackwell, pp. 245-306.

COLLISCHONN, G. 2007. Proeminência acentual e estrutura silábica: seus efeitos em fenômenos do português brasileiro. Gabriel Antunes de Araújo (org.) O acento em português. São Paulo: Parábola.

CRISTÓFARO-SILVA, T. 2001. Difusão Lexical: Estudo de Casos do Português Brasileiro. E.A.M. Mendes, P.M. Oliveira e V. Benn-Ibler (orgs). O Novo Milênio: interfaces lingüisticas e literárias. Faculdade de Letras. Belo Horizonte, pp. 209-218.

FRANÇOZO, E.; OLIVEIRA, L.F.; RUIZ, L.G.; LIMA, P.L.C; NAVAS, A.L.G.P. 2002. Conhecimento Lexical e Processamento da Linguagem. Reunião Anual do GEL, 2002, São Paulo. Anais da $25^{a}$ Reunião Anual do GEL. São Paulo: GEL.

GOLDSMITH, J. 1990. Autosegmental and Metrical Phonology. Oxford: Blackwell.

IBGE (Instituto Brasileiro de Geografia e Estatística). Disponível em: $<$ http://www.ibge.gov.br/home/>

LABOV, W. 1972. Sociolinguistic Patterns. Philadelphia: University of Pensilvania Press.

LABOV, W. 1994. Principles of linguistic change, vol. I, Internal factors. Malden and Oxford: Blackwell Publishers.

LABOV, W. 2001. Principles of linguistic change, vol. II, Social factors. Malden and Oxford: Blackwell Publishers.

LEAL, E.G. 2006. Elisão silábica e haplologia: aspectos fonológicos do falar da cidade paulista de Capivari. 165f. Dissertação (Mestrado em Semiótica e Linguística Geral) - Universidade de São Paulo, FFLCH, São Paulo.

LEAL, E.G. 2007. A queda da sílaba: análise do contexto consonantal pela geometria de traços. Revista Virtual de Estudos da Linguagem - ReVEL. Edição especial n. 1. Disponível em: <www.revel. inf.br>.

LEAL, E.G. 2012. Teoria fonológica e variação: a queda de sílaba em Capivari e em Campinas. 242f. Tese (Doutorado em Semiótica e Linguística Geral) - FFLCH-USP, São Paulo, 2012.

LEAL, E.G. 2018. Variação e definição de queda de sílaba: o contexto segmental em Capivari-SP e Campinas-SP. Revista de Estudos da Linguagem, Belo Horizonte, v. 26, n. 1, pp. 187-220.

LEBEN, W. 1973. Suprasegmental Phonology. Ph.D. Dissertation. MIT: Cambridge, Massachusetts. 
MENDES, R.M.G. 2009. A haplologia no português de Belo Horizonte. Dissertação (Mestrado), Belo Horizonte: PUCMINAS.

McCARTHY, J. 1979. On stress and syllabification. Linguistic Inquiry 10: 443-465.

McCARTHY, J. 1986: OCP effects: Gemination and antigemination. Linguistic Inquiry 17, pp.207-63.

McCARTHY, J. 1988. Feature geometry and dependency: A review. Phonetica 45: 84-108.

NESPOR, M.; VOGEL, M. 1986: Prosodic phonology. Dordrecht: Foris Publications.

OLIVEIRA, A.J. 2012. 'Comendo o final das palavras': Análise variacionista da haplologia, elisão e apócope em ltaúna/MG. Tese de doutorado. Belo Horizonte, UFMG.

OLIVEIRA, A.J.; VIEGAS, M.C. 2013. Casos especiais de elisão silábica: Uma contribuição aos estudos de gramaticalização. In VIEGAS, M. do C. (Org.). Minas é singular. Belo Horizonte: Faculdade de Letras da UFMG.

OLIVEIRA, M.; PAZ, F. 2013. Haplologia na região amazônica: Imagens preliminares. Estudos de Lingüistica Galega 5, pp. 69-87.

PAVEZI, V.C. 2006. A haplologia na variedade paulista. Dissertação de mestrado. São José do Rio Preto: Unesp.

PAZ, F.H.S. 2013. Haplologia no falar paraense. Dissertação (Mestrado) - Universidade Federal do Pará, Belém.

Prefeitura Municipal de Campinas. Disponível em: $<$ http://www.campinas.sp.gov.br/ $>$

Prefeitura Municipal de Capivari. Disponível em: $<\underline{\text { http://www.capivari.sp.gov.br }>>}$

SANDALO, F.; TRUNKENBRODT, H. 2002. Some notes on phonological phrasing in Brazilian Portuguese. The MIT Working Paper, Cambridge, v.42, p. 285-310.

SANKOFF, D.; TAGLIAMONTE, S.; SMITH, E. 2005. Goldvarb X: A variable rule application for Macintosh and Windows. Department of Linguistics, University of Toronto.

SELKIRK, E.O. 1984. Phonology and Syntax: the relation between sound and structure. Cambridge, Mass: MIT Press.

SIMIONI, T.; AMARAL, F.U. 2011. A haplologia e o princípio do contorno obrigatório. In.: MARTINS, Marco Antônio (Org.). Revista do GELNE, v.13, p. 53-67.

TAGLIAMONTE, S.A. 2006. Analysing Sociolinguistic Variation. Cambridge: Cambridge University Press.

TENANI, L.E. 2002. Domínios prosódicos no português do Brasil: implicações para a prosódia e para a aplicação de processos fonológicos. Tese de doutorado. Campinas, Unicamp.

TENANI, L.E. 2003. Haplologia e domínios prosódicos. Letras de Hoje, Porto Alegre: Edipucrs.

TENANI, L.E. 2006. Considerações sobre a relação entre processos de sândi e ritmo. Estudos da Língua(gem), Vitória da Conquista, v. 03, p. 105-122. 